This is the peer reviewed version of Hoult, N.A. and Lees, J.M. (2011) "Time-dependent Behaviour of RC beams Retrofitted with CFRP Straps" ASCE Journal of Composites for Construction v. 15, (1):75-84 which has been published on http://dx.doi.org/ 10.1061/(ASCE)CC.1943-5614.0000155

\title{
Time-dependent behaviour of RC beams retrofitted with CFRP straps
}

\author{
Neil A. Hoult ${ }^{1}$ and Janet M. Lees ${ }^{2}$
}

\begin{abstract}
A retrofitting technique that uses prestressed unbonded CFRP straps to provide additional shear capacity has previously been shown to be successful under short-term static loading conditions. The current study explores the longer-term behaviour of this retrofitting technique through two experiments (a sustained load and a cyclic load experiment) and the development of a model based on the modified compression field theory. The experiments indicated that the strain in the CFRP straps changes with time due to changes in the load sharing with the concrete (caused by creep) and the steel stirrups (caused by yield of these elements). The predictive model was initially validated against static experimental results before being applied to the longer-term experiments. The model predicts the trends in behaviour well although it is conservative in its estimates of strap strain. The model was then used to determine the influence of stirrup yielding, the load level before and after retrofitting, and the duration of loading, on the CFRP strap strains. The initial results suggest that the largest increases in longterm strap strain will occur when the straps are installed early in the structure's service life although further experimental validation is required.
\end{abstract}

CE Database subject headings: Fiber reinforced polymers, Shear, Concrete beams, Creep, Sustained loading

\footnotetext{
${ }^{1}$ Assistant Professor, Department of Civil Engineering, Queen’s University, Ellis Hall, Kingston, On., Canada, K7L 3N6. E-mail: neil.hoult@gmail.com

${ }^{2}$ University Senior Lecturer, Department of Engineering, University of Cambridge, Trumpington St., Cambridge,

UK, CB2 1PZ. E-mail: jmL2@eng.cam.ac.uk
} 


\section{Introduction}

Civil engineers have a role to play in addressing climate change and developing ways to reduce the carbon footprint of the built environment. One effective way to do this is to extend the lives of existing structures so as to as amortize their carbon footprints over as long a period of time as possible. However, for many reinforced concrete structures this is not possible without intervention due to their inadequate shear force carrying capacity. These inadequacies may be due to increased loading on the structure, decreased capacity due to corrosion of the internal transverse reinforcement or an assessment suggesting that the structure does not meet more conservative current code requirements. Regardless of the cause, in order to keep the structure in service additional reinforcement must be installed or weight limits imposed.

Over the past few decades, extensive research has been carried out to investigate the possibility of retrofitting reinforced concrete structures using FRPs. FRP shear strengthening systems include the use of epoxy bonded sheets (e.g. Triantafillou 1998), plates (e.g. Czaderski and Motavalli 2004) or near surface mounted reinforcement (e.g. De Lorenzis and Nanni 2001). The disadvantage of many of these techniques is that if the FRP reinforcement is only bonded to the web of the beam, it does not provide as much of a capacity enhancement as when the section is fully wrapped (e.g. Melo et al. 2003). An unbonded CFRP strap retrofitting system first developed by Winistoefer (1999) is an alternative approach. In the shear strap system, layers of thin CFRP tape are wrapped around pad supports on a beam as illustrated in Fig. 1 or, in an under-slab installation (Hoult and Lees 2009), slotted through a profile formed in the concrete as illustrated in Fig. 2. Because the tape is thin $(0.16 \mathrm{~mm})$ it can be wrapped around the section multiple times with the total number of layers being dictated by the required additional shear capacity to be provided by the CFRP. Once the desired number of layers has been placed around the beam, the outermost tape layer is fusion bonded to the next tape layer to form a closed outer loop but the remaining layers stay non-laminated to reduce undesirable stress concentrations. This closed loop is referred to as a "strap." The straps are not bonded to the concrete but instead apply pressure to the top and bottom pads which transfer a compressive transverse force into the concrete. The straps can be also prestressed, which is especially beneficial for deep beams (Stenger 2000). The strap retrofitting system has been proven to provide significant shear 
strength enhancement to reinforced concrete rectangular (Kesse and Lees 2007), deep (Stenger 2000) and T-beams (Hoult and Lees 2009). However, to date the experimental validation work using the CFRP straps has primarily focused on quasi-static testing to destruction of the beam specimens to determine their ultimate load carrying capacity.

The current study presents a preliminary set of tests that were undertaken in order to determine the effects of long-term loading on T-beams retrofitted with the CFRP straps. In this initial study, the results of a sustained and cyclic load test are compared with static test results and it was found that the CFRP strap strains change with time. Given the brittle nature of the FRP it is important to understand the time-dependent evolution of the strap strains to avoid a premature failure of the FRP transverse reinforcement. This is the first time this behaviour has been identified for the CFRP strap system used here but the implications are likely to apply to other FRP strengthening systems as well. A potential method to predict these time-dependent strains based on the modified compression field theory (MCFT) (Vecchio and Collins 1986) is proposed. The predictive approach is initially verified against the experimental static test results and the time-dependent predictions are then assessed against the longer-term sustained and cyclic load tests. The model will be validated using both deflection and strain data but it is the prediction of the FRP strain data that is of greatest concern and the motivation for the model development. A preliminary parameter study to identify the predicted changes in the FRP reinforcement strain during the lifetime of a reinforced concrete structure is also presented.

\section{Deflections and transverse reinforcement strains}

In unstrengthened reinforced concrete beams with span/depth ratios greater than three, shear deflections typically represent a relatively small component of the total deflection and hence most short and long-term serviceability calculations do not include an allowance for shear deformations. In CFRP-shear strengthened beams where the shear demand is high, the shear deflections may become much more significant as there will a greater demand on the transverse reinforcement contribution. Furthermore, since an existing structure may already be cracked in shear the concrete stiffness will be reduced which will contribute to larger shear deflections and influence the force in the transverse CFRP reinforcement over the short- and long-term. Due to 
the brittle nature of the CFRP material, it is of particular importance to understand any timedependent load-sharing aspects as this may dictate the initial allowable strains in the CFRP reinforcement.

The prediction of shear deflections and strains in cracked reinforced concrete members is difficult due to the inherent complexities associated with tension stiffening, material variability and non-linear time-dependent material properties. In the following, predictions using an established model for the calculation of flexural deflections will be combined with a shear deflection model to assess the long-term behaviour of CFRP strengthened beams.

\section{Flexural deflections}

The calculation of flexural deflections in steel-reinforced concrete beams is fairly well established in design codes such as the procedure given in ACI 318 (2008). For example, for a simply-supported beam with two point loads, the mid-span deflection, $\Delta_{\text {mid-span }}$, can be calculated using the approach from ACI 318 (code equation numbers are given in square brackets) as:

$$
\Delta_{\text {mid-span }}=\frac{P a}{24 E_{c} I_{\text {eff }}}\left(3 l^{2}-4 a^{2}\right)
$$

where $P=$ applied load $(\mathrm{N})$

$$
\begin{aligned}
& a=\text { shear span length }(\mathrm{mm}) \\
& l=\text { total span }(\mathrm{mm}) \\
& E_{c}=4700 \sqrt{f_{c}^{\prime}}(\mathrm{MPa}) \\
& f_{c}^{\prime}=\text { compressive cylinder strength of the concrete (MPa) } \\
& f_{t}=0.623 \sqrt{f_{c}^{\prime}}(\mathrm{MPa})[9-10] \\
& I_{e f f}=\left(\frac{M_{c r}}{M_{a}}\right)^{3} I_{g}+\left(1-\left(\frac{M_{c r}}{M_{a}}\right)^{3}\right) I_{c r} \\
& M_{c r}=f_{t} I_{g} / y=\text { the cracking moment }(\mathrm{Nmm}) \text { [9-9] }
\end{aligned}
$$


$M_{a}=$ the applied moment - taken as the maximum moment (Nmm)

$I_{g}=$ the gross second moment of area $\left(\mathrm{mm}^{4}\right)$

$I_{c r}=$ the cracked second moment of area of the transformed section $\left(\mathrm{mm}^{4}\right)$

$y=$ the distance from the centroid to the tension face $(\mathrm{mm})$

Time-dependent creep effects can be taken into account through the use of a multiplier which relates the deflection at time $t=0$ with the deflection at time $t$ (ACI-318 2008). The resulting expression for the long-term deflection relationship is expressed as

$$
\delta_{t}=\delta_{o}\left(1+\frac{\xi}{1+50 \rho_{c}}\right)[9-11]
$$

where $\delta_{t}=$ the deflection at time $t(\mathrm{~mm})$

$\delta_{o}=$ the initial flexural deflection at time $t=0(\mathrm{~mm})$

$\xi=$ a factor to account for the duration of loading

$\rho_{c}=A_{c} / b_{w} d=$ the compressive reinforcement ratio

$A_{c}=$ the area of compressive reinforcement $\left(\mathrm{mm}^{2}\right)$

Within the code, the suggested values for $\xi$ at three months, six months, one year and five years are 1, 1.2, 1.4 and 2 respectively. The ACI approach was calibrated using specimens with larger $a / d$ ratios including T-beams ( $\mathrm{Yu}$ and Winter 1960). However it is felt by the authors to be an appropriate approach as long as two criteria are met: (i) plane sections remain plane and (ii) the beam detailing allows for reasonable crack control. As will be described in the experimental sections, the beams considered in the current work have $a / d$ ratios of 3.3 and the main longitudinal steel bars are deformed with an appropriate concrete cover. It is therefore expected that beam action prevails and that the flexural cracking can be assumed to be well controlled so

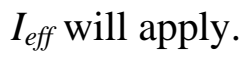




\section{Shear Deflection Models}

The main categories of shear deflection design models for reinforced concrete beams include truss models, cracked element models and non-linear finite element (NLFE) analyses. NLFE analyses introduce additional computational complexity, there is uncertainty about appropriate material models, and can have limitations in terms of their ability to predict the strain in the CFRP straps (Kesse and Lees 2007) so they will not be considered further in the current work.

Truss models based on work by Dilger (1967) have been applied to predict shear deflections (Neville et al. 1983; Nie and Cao 2000; Ueda et al. 2002). In these truss models, the shear deflections in a beam are the result of compression causing the concrete strut to contract while the tension in the ties causes the transverse reinforcing elements to elongate. Truss models have several advantages including the fact that they are computationally straightforward, creep or shrinkage of the concrete strut can be readily incorporated and, with certain assumptions regarding the load sharing, the models can be used to determine the strains in the transverse reinforcement directly. However, when extending these truss models to predict the long-term behaviour of CFRP strengthened beams, the load sharing issue becomes problematic. The relative proportions of shear load carried by the steel and concrete in a CFRP strengthened beam may differ from that expected in conventional RC structures since the interactions will depend on the transverse reinforcement bond conditions, the relative reinforcement stiffness and reinforcement ratios. Also, in the truss models as currently formulated, there is no timedependent influence on the strain in the transverse reinforcement. A further complication is that the incremental load sharing between the CFRP and steel will change when any transverse steel yields.

An alternative approach is to consider a cracked reinforced concrete element. The cracked element can be assigned constitutive material properties and needs to satisfy equilibrium and compatibility constraints. This approach would be consistent with a model such as the Modified Compression Field Theory (MCFT) (Vecchio and Collins 1986) which has previously been formulated to include, in an average sense, prestressed CFRP straps (Lees et al. 2002). However, the MCFT is iterative which introduces additional evaluation requirements and the 
question of how best to reflect the time-dependency remains. Nevertheless, the compatibility conditions within the MCFT allow for the interactions between strains to be directly identified and, as such, the MCFT was selected for further investigation.

\section{Modified Compression Field Theory}

Full details of the MCFT can be found elsewhere (Vecchio and Collins 1986). Only the modifications required in the current work to incorporate the CFRP straps and time-dependent strains will be highlighted as illustrated in the boxed equations in Fig. 3. It is also worth noting that the sign convention in Fig. 3 is tension and compression positive.

\section{Inclusion of CFRP straps}

The CFRP transverse straps are linearly elastic, unbonded and potentially prestressed. The MCFT considers the average strain in the reinforcement elements and as such is ideal for modelling the straps. Because the straps are unbonded, the strain in the straps (excluding the strain due to prestress) is by definition the average transverse reinforcement strain over the full height of the strap. The transverse strain, $\varepsilon_{z}$, from the MCFT will reflect the average strain in the CFRP strap due to crack opening and the total strap strain is then, $\varepsilon_{O}+\varepsilon_{Z}$, where $\varepsilon_{o}$ is the initial prestress. The corresponding stress in the CFRP strap $f_{f z}$ is then calculated using the elastic modulus of the strap $E_{f}$ where $f_{f z}=E_{f}\left(\varepsilon_{z}+\varepsilon_{o}\right)$ with a limit equal to the breaking stress of the strap $f_{u z}$. The straps are located at a discrete spacing along the shear span however in the model they are assumed to be smeared over the shear span. Provided the strap spacing is fairly uniform and the distance between straps is not excessive, an average uniform stress should be a reasonable approximation of the applied vertical strap stresses. If the influence of the CFRP straps is averaged over the element, the resulting total stress in the vertical direction, $f_{z}$, is:

$$
f_{z}=\rho_{z} f_{s z}+\rho_{f} f_{f z}+f_{1}-v \tan \theta
$$

where

$$
\rho_{f}=\frac{A_{F R P}}{b_{w} s_{F R P}} \quad \text { and } \quad \rho_{z}=\frac{A_{s v}}{b_{w} s_{v}}
$$




$$
\begin{aligned}
& A_{F R P}=\text { area of CFRP strap }\left(\mathrm{mm}^{2}\right) \quad \text { and } \quad A_{s v}=\text { area of transverse steel }\left(\mathrm{mm}^{2}\right) \\
& S_{F R P}=\text { CFRP strap spacing }(\mathrm{mm}) \quad \text { and } \quad S_{V}=\text { transverse steel spacing }(\mathrm{mm}) \\
& f_{S Z}=\text { stress in the transverse steel } \leq f_{\text {yield }} \quad f_{1}=\text { principal tensile stress } \\
& v=\text { applied shear stress }
\end{aligned}
$$

In the MCFT cracked element approach, the beam web is assumed to carry the shear force. Thus a T-beam is considered to be equivalent to a rectangular beam with the same web width. For the T-beams considered here the strap only encloses the web region which is consistent with the assumption of a web-only contribution to shear but this assumption will not take into account any beneficial effects of the flange.

\section{Time-dependent effects}

Even if time-dependent changes in the material properties occur, the MCFT equilibrium equations still hold, albeit the angle of the concrete strut etc. may change. Any creep in the steel reinforcement and the CFRP straps (Winistoerfer 1999) will be assumed to be negligible in comparison with the concrete creep effects so the CFRP and steel stress-strain relationships require no modifications. The steel was assumed to be elastic perfectly plastic and the CFRP linear-elastic brittle.

Collins and Mitchell (1987) suggest the influence of long-term and/or repeated loading on the average tensile strength in the concrete can be reflected using a factor $\alpha_{2}$ where $\alpha_{2}=1.0$ for short-term monotonic loading and $\alpha_{2}=0.7$ for sustained or repeated loads resulting in:

$$
f_{1}=\frac{\alpha_{1} \alpha_{2} f_{c r}}{1+\sqrt{500 \varepsilon_{1}}}
$$

where

$$
\begin{aligned}
& f_{c r}=\text { the cracking stress }(\mathrm{MPa})=0.33 \sqrt{f_{c}^{\prime}} \\
& f_{c}^{\prime}=\text { the uniaxial compressive cylinder strength }(\mathrm{MPa}) \\
& \alpha_{1}=\text { a bond factor where } \alpha_{1}=0.7 \text { for plain bars and } \alpha_{1}=1.0 \text { for deformed bars }
\end{aligned}
$$


If the change from $\alpha_{2}=1.0$ to 0.7 occurs over time, then a continuous time-dependent function would be more accurate. But in the current work, $\alpha_{2}$ was fixed as 1.0 for the short-term tests and as 0.7 throughout the long-term tests. The choice of 0.7 will be conservative in the earlier stages of any long-term test but more representative of the longer-term behaviour which is of most interest.

Compressive creep in the concrete depends on many factors including the applied stress, specimen size, humidity and age at loading. Creep would act to increase the principal strain in the compressive strut $\varepsilon_{2}$ for a given stress $f_{2}$. In the MCFT, the relationship between principal concrete stress and strain can be modified using a creep factor where

$$
\varepsilon_{2}=\varepsilon_{c}^{\prime}\left(1-\sqrt{1-\frac{f_{2}}{f_{2 \max }}}\right)\left(1+\phi\left(t, t_{i}\right)\right)
$$

$\varepsilon_{C}^{\prime}$ is the compressive strain at the peak stress which will be taken as 0.002 in the current work and the creep factor is defined as (Collins and Mitchell 1987):

$$
\phi\left(t, t_{i}\right)=3.5 k(1.58-H / 120) t_{i}^{-0.118} \frac{\left(t-t_{i}\right)^{0.6}}{10+\left(t-t_{i}\right)^{0.6}}
$$

And $\quad t=$ time under consideration (days)

$t_{i}=$ age at initial loading (days)

$H=$ relative humidity

$k=$ volume to surface ratio factor

There may also be sustained loading influences on the ability of a crack to transfer shear stresses, a requirement of the MCFT. In the examples that will be described here, the crack shear stress was generally not a limiting condition in the load ranges considered so, as an initial assumption, it will be assumed that the shear transfer is unchanged as a result of time-dependent loading. 
Note that the MCFT equations associated with crack widths and stresses at the crack have been omitted from Fig. 3 for brevity. No allowance has been made for shrinkage effects.

\section{Flexure/shear interactions and ultimate failure}

The previous sections have focused on the behaviour of a 'smeared' cracked element in pure shear. Any applied bending moment will result in additional longitudinal strains, $\varepsilon_{X}$. To reflect this accurately, sectional analyses are required which could be done using an analysis package such as Response 2000 (Bentz 2000) for unstrengthened reinforced concrete beams. Although CFRP prestressed straps cannot currently be modelled in this package, the programme could be extended to include this additional reinforcement. To avoid the need to explicitly consider curvatures, the flexural and shear behaviour were decoupled and considered separately in the current approach. The advantage is that the moment influence on $\varepsilon_{X}$ does not need to be incorporated into the MCFT shear formulation and the ACI equations can be used to predict the changes in flexural deflection. The results from the two analyses can then be superposed. The disadvantage is that the interactions between the two will not be reflected. This will be a particular concern at high shear forces or moments and, as such, represents a limitation of the approximation.

The ultimate failure behaviour is a further issue. Other studies have suggested that the MCFT may underpredict the ultimate load capacity of CFRP strengthened T-beams (Hoult and Lees 2007; Lees et al. 2002), possibly due to shear/flexure interactions, high longitudinal reinforcement ratios and the influence of the compression flange in later stages of loading. As the main focus of the current work is the prediction of the shear deflections and the timedependent behaviour of a strengthened structure in service, and the proposed approach does not consider flexure/shear interactions, the ultimate failure behaviour will not be investigated.

Using the equations detailed, the solution procedure broadly follows that suggested by Collins and Mitchell (for further details see Collins and Mitchell 1987). As we are seeking to compare experimental results with theoretical predictions, the requirement in the current work is to find a

solution for a given applied shear load $V$. By iterating through various combinations of $\varepsilon_{1}$ and $\theta$, 
the required solution can be found by ensuring the resultant shear force equals $V$ and there is no net axial force on the member. The resulting shear deflection is then the converged shear strain, $\gamma_{x Z}$, multiplied by the shear span, $a$, in the case of a beam loaded in 4-point bending.

\section{Experimental Case Study}

To highlight the nature of the shear deflections and time-dependent load-sharing behaviour, a case study considering an unstrengthened control beam, B1 (referred to as B1/25 in Hoult and Lees 2009), two short-term static, B6 and B7, (referred to as B6/30/C/44 and B7/30/G/36 respectively in Hoult and Lees 2009) and two long-term loading tests B8 and B9 conducted on T-beam specimens with the geometry illustrated in Fig. 2 will be presented. One of the long-term specimens (B8) was subjected to a sustained load whereas the other (B9) was tested under cyclic loading. The set-up and initial loading results of the long-term tests have been discussed elsewhere (Hoult and Lees 2005) and so only the salient details are presented here.

The concrete properties (i.e. the cube strength, $f_{c u}$, the associated cylinder strength, $f_{c}{ }_{c}$, based on multiplying $f_{c u}$ by 0.8 and the modulus of rupture strength, $f_{r}$ ), shear force at failure and failure mode for the specimens are given in Table 1. The shear force at failure and failure mode of the specimens are included to illustrate the enhancement provided by the straps although the ultimate behaviour will not be dealt with here as the discussion focuses on the long-term behaviour. The measured steel reinforcement $0.2 \%$ offset yield/ultimate strengths for the 6, 8, 16 and $20 \mathrm{~mm}$ steel reinforcing bars were 578/646MPa, 467/540MPa, 505/586 MPa and 523/633 MPa respectively. The elastic modulus in each case was approximately $200 \mathrm{GPa}$.

The CFRP straps were formed by wrapping the $12 \mathrm{~mm}$ wide by $0.16 \mathrm{~mm}$ thick tapes around the beam multiple times and fusion bonding the outer-most tape layer to the next outermost layer to form a closed 10 layer strap. The resulting strap has a total cross sectional area of $38.4 \mathrm{~mm}^{2}$, a modulus of elasticity of $121 \mathrm{GPa}$, an ultimate tensile strength of 1,544 MPa and a rupture strain of 0.0127 . Three straps were installed in both shear spans at a spacing of $200 \mathrm{~mm}$ for B7, the sustained and cyclic specimens (B8 and B9) and 250mm for the static specimen B6 as illustrated in Fig. 2. The straps were prestressed with an initial force of approximately $25 \%$ of the strap 
ultimate stress $(\sim 15 \mathrm{kN})$. Strain gauges were applied to the CFRP straps and the transverse steel at mid-height, and the longitudinal steel at mid-span.

\section{Loading Tests}

All the specimens were tested in four point bending. In the unstrengthened and strengthened static tests, the beams were placed in a test rig and loaded to failure over a period of approximately 2 hours. The sustained loading specimen was loaded 90 days after casting in four-point bending using tensioned steel rods connected to a strong floor and a system of spreader beams. The specimen was subjected to two sustained point loads of $110 \mathrm{kN}$ each for 260 days. It is worth noting that $110 \mathrm{kN}$ is above the $88 \mathrm{kN}$ capacity of the unretrofitted beam B1 with otherwise similar properties (Hoult and Lees 2009). The cyclic load specimen was tested approximately 160 days after casting using a self reacting frame. The two point loads were cycled between a minimum of 70 and a maximum of $110 \mathrm{kN}$ for 2.1 million cycles. This loading scheme meant that the mean load $(90 \mathrm{kN})$ was approximately the same as the capacity of the unretrofitted specimen and was deemed to be an extreme example of the loading on such a retrofitted structure.

\section{Experimental Results and Predictions}

The short-term and long-term experimental results were compared with the MCFT predictions to identify the accuracy of the predictions.

\section{Short-term static behaviour}

In a typical experimental static test, the test will be stopped at selected load stages in order to take photographs, trace cracks in a safe manner and observe any changes in behaviour. During this stoppage time, creep will occur and, in displacement control, the load will drop off. On reloading, additional displacement will then be apparent from the load-displacement curve. Thus 
there exists a component of creep behaviour even in a 'static' test to failure. Any changes due to short-term creep would be expected to be most prevalent at higher loads.

Fig. 4(a) shows the measured deflection for specimen B6 at mid-span. Two sets of experimental data have been plotted: the raw experimental results and the experimental results after the deflections due to short-term creep have been removed. To adjust the results for short-term creep, the difference between the deflection measured at the beginning of the load stage (i.e. when the load is first attained) and the deflection measured at the end of the load stage (i.e. when the load is attained a second time on the way up to the next load) is subtracted from the raw results. This adjustment was required to provide a like-for-like comparison with the short-term predictions which assumed no creep. The short-term deflections based on the ACI prediction (equation 1) alone and the result obtained by adding the MCFT shear prediction to the ACI prediction, hereafter referred to as the 'combined' model, are also plotted on the figure. In practice the experimental beams include disturbed regions around the load points and the transverse reinforcement is discrete. However, in the MCFT a typical undisturbed element in the shear span with 'smeared' reinforcement has been assumed to be representative of all sections within the shear span.

The ACI flexural prediction underestimates the experimental results and the deviation becomes more pronounced at higher load levels. Fig. 4(b) shows the experimental deflections with shortterm creep effects removed and the analytical results, along the span at two different load levels: $70 \mathrm{kN}$ and $110 \mathrm{kN}$. The difference in the experimental and the ACI flexural deflection is constant in the constant moment region but varies in the shear spans which further confirms the shear component of the deflection. It is also of note that at $110 \mathrm{kN}$ the shear deflection represents $14 \%$ of the overall mid-span displacement indicating that the shear deflections are not insignificant. It can be seen that in both figures the 'combined' predictions match well.

The central region of the beam shear span incorporating the middle CFRP strap was felt to be the most representative region in which to compare the MCFT predicted strains and the experimental strains measured from strain gauges on the CFRP strap and the internal steel stirrups for beams B6 (Fig. 5(a)) and B7 (Fig. 5(b)). In theory, the average stirrup strain and the strap strain should 
be the same. The observed difference in measured strains is believed to be due to the fact that the stirrup is embedded in the concrete. Therefore the stirrup strain is bounded between a minimum value (between the cracks where the concrete shares the load) and a maximum value (at the crack where the strain will eventually exceed the yield strain). The strain that is used in the MCFT is an average strain that lies between these two bounds whereas the strain that is measured depends on several factors including the location of the strain gauge relative to the crack and the level of debonding. The stirrup strain in both graphs is lower than predicted by the MCFT and increases at a slower rate. One contributing factor could be that the strain gauge was not located at a crack location but was instead located between cracks, which results in a lower strain increase with load. However the measured strain shows the expected trend in behaviour with very little initial strain when the concrete is uncracked followed by an increase in strain rate after cracking. The strain rate then begins to increase further as the crack opens and load is transferred from the concrete into the stirrup as the specimen approaches the failure load. Interestingly, if one compares the stirrup strain to the strap strain (which can be considered the experimental average strain due to the unbonded nature of the strap), one can see that the stirrup strain is initially higher than the average strain but then increases at a lower rate. Here again the location of strain gauge will affect the result since if the strain gauge is close to but not at the crack, a significant strain increase will be measured when the shear crack initially forms. However, tension stiffening will result in a reduced rate of strain increase if the gauge is not at the crack.

The strain in the strap, on the other hand, should be theoretically much closer to the MCFT strain as the strap strain should be an average strain because it is unbonded. The model appears to capture the correct trends in the behaviour although the predictions overestimate the actual strain values. There a number of factors that could affect the strains predicted by this model including: (i) the variable nature of crack formation in concrete which will alter the strains in both the stirrups and the CFRP straps; (ii) strain gauge placement for the embedded reinforcement (as discussed above); (iii) the influence of prestressing in the CFRP straps on the concrete contribution to shear capacity; and (iv) the fact that the specimens are T-beams which affects the shear behaviour (Zoeheary et al. 1998) but is not explicitly accounted for in the MCFT. The fact that the slope of the MCFT prediction corresponds quite closely to the measured strap strain suggests that there is an additional load carrying mechanism that creates an offset between the 
actual strains and the predicted strains. This could be a result of, for example, the fact that the specimens were T-beams with additional shear force carrying capacity (Zoeheary et al. 1998) that is not accounted for by the MCFT. In order to fully understand the implications of each factor a large-scale comprehensive testing program would be required. However, the current model reveals the dependency of CFRP transverse reinforcement strain on the concrete contribution and the long-term concrete behaviour as will be investigated in the next section. It also appears to provide a conservative estimate of the strap strains which is appropriate for use in design.

\section{Long-term behaviour}

Since the flexure/shear model seemed to predict the short-term static results fairly well, the combined deflection model was then used to predict the immediate and long-term deflections for the sustained and cyclic load specimens. The $\xi$ value used in eqn 2 was determined for a range of time increments by interpolating from a plot of $\xi$ versus duration of loading in months on a logarithmic scale. The value of $\phi$ in equation 6 , which was used to calculate the time dependant shear deflections, was evaluated using the appropriate time values for each specimen.

The results of the mid-span deflection comparison for B8 under a sustained load over a period of 260 days are presented in Fig. 6(a). The model underestimates the initial creep deflections as indicated by the much steeper slope of the initial experimental results but accounts for the longterm trends well. One potential reason that the prediction underestimates the initial deflection is again due to short-term creep. It was noted that during loading (the load was applied by tightening nuts on threaded rods as detailed in Hoult and Lees (2005)) that after a certain load was obtained, the measured load would immediately start to reduce. This was especially true near the sustained load of $110 \mathrm{kN}$ as the nuts had to be retightened a number of times before the load remained relatively constant. As such, by the time the required sustained load was reached, a portion of the measured deflection was already due to creep. The potential for this short-term creep effect is illustrated in Fig. 4(a), which shows the deflection of specimen B6 at 110kN. One can see that the creep adjusted deflection of the specimen is $12 \mathrm{~mm}$, which is quite close to the $11.6 \mathrm{~mm}$ of initial deflection for B8 as predicted by the model. The actual deflection of B6 is 
$1.75 \mathrm{~mm}$ higher than the creep adjusted deflection, which while not as significant as the difference between the actual and predicted initial deflections for B8, still illustrates the impact of short-term creep. The reason for the more significant deflection difference for B8 is felt to be due to the longer duration of loading before a deflection measurement was taken for this specimen. A further source which may contribute to the discrepancy in the predicted and measured early stage load deflection behaviour is believed to be the fact that the $\xi$ factor was extrapolated from data given for longer term loading and so may not be appropriate for the early stages of creep behaviour. Fig 6(b) presents a semi-log plot of the middle strap, middle stirrup and predicted strains versus time behaviour for B8. The model overestimates the strains, which would be conservative, but captures the trend in behaviour well.

To model the long-term deflection of the Cyclic specimen, B9, a multiplier for a duration of loading equal to 12 days was taken as 1.21 for the flexural deflection. Both the measured and predicted deflections for the cyclic load specimen at $t=0$ and after 2.1 million cycles ( $t=12$ days) are shown in Table 2. The deflection after 2.1 million cycles was found to be less than that of the sustained load specimen. This was attributed to the longer duration of loading for the sustained specimen (260 days versus 12 days for the sustained and cyclic load specimens respectively) and the higher mean applied load $(110 \mathrm{kN}$ versus $90 \mathrm{kN})$ for that specimen. The deflection along the length of B9 at a load of $110 \mathrm{kN}$ before and after cycling has been plotted in Fig. 7. As was seen in Fig. 4(b), using a model based purely on flexural deflections underestimates the total deflection. The figure also illustrates that the difference in deflection predictions occurs mostly in the shear spans and once the combined flexure and shear model is used the prediction accuracy increases dramatically. Finally, the figure shows that the long-term model does a good job of predicting the effects of creep on the deflection. The measured minimum and maximum middle CFRP strap strains versus number of load cycles for the Cyclic load specimen are presented in Fig. 8. The experimental strap strain increases as the test progresses. At approximately 900000 cycles there is a small spike in the data corresponding to a point when the specimen was unloaded and realigned in the testing rig. This increase is possibly due to a widening of the crack caused by damage along the crack when the specimen was completely unloaded. At around 1.6 million cycles there is an increase in strain in the middle strap. This is believed to be due to the internal steel shear reinforcement yielding and shedding 
load to the surrounding straps. Unfortunately, the strain gauge on the steel shear reinforcement failed at 1.3 million cycles (which may in itself be an indication of increasing strains in this element) making it impossible to compare the two strain results. However, the maximum strain in the element, before gauge failure, of 0.0022 is close to the strain at which the stiffness begins to change for this steel, which does not have a well defined yield plateau. Also presented in this figure is an estimate of the strap strain where the mean applied shear force of $90 \mathrm{kN}$ was used in the model to predict the strain increase over time. Since the beam is cycling between a minimum and maximum load, the minimum and maximum strains are then estimated by adding or subtracting the initial strain offset between $70 \mathrm{kN}$ and $90 \mathrm{kN}$, and between $90 \mathrm{kN}$ and $110 \mathrm{kN}$ calculated at time $=0$ to the time dependent strain calculated using $90 \mathrm{kN}$. That is to say, it was assumed that the difference between the minimum strain and the maximum strain remains constant and only the average strain varies with time.

Although the creep-based model appears to capture the salient trends in behaviour for the cyclic loading specimen, it does not explicitly consider the effect of other potential factors related to cyclic loading such as deterioration along the crack interface. However, as noted earlier the model does provide a conservative prediction of the strap strain, which would be appropriate for design.

\section{Parametric Studies}

The experimental results suggest that a cracked element approach has the potential to predict the long-term deflection and strain behaviour. Further parametric studies were therefore conducted to investigate the conditions under which long-term sustained loading would result in the yielding of the internal reinforcing steel and the implications for the CFRP strains, and the influence of the age of the structure when additional loading takes place on the strap strains.

To consider the question of the yielding of the internal transverse reinforcement three cases were investigated: (i) a Base Case where the specimen parameters were the same as for specimen B8, (ii) Case A where the compressive strength and strap prestress were decreased by $10 \%$ while the transverse reinforcement spacing and $\phi\left(t, t_{i}\right)$ were increased by $10 \%$ and (iii) Case B where the 
compressive strength and strap prestress were increased by $10 \%$ while the transverse reinforcement spacing and $\phi\left(t, t_{i}\right)$ were decreased by $10 \%$. In each case, the applied shear was taken as $100 \mathrm{kN}$, the strengthening was applied from the outset, and the strains were evaluated at 0, 10, 50, 100 and 260 days as well as 1, 5, 10 and 20 years. The results of this study are presented in Fig. 9(a), which presents the relationship between transverse strain and the principal strain angle for the three cases and load durations. It can be seen that Case A results in higher initial strains as well as larger increases in strains with time. In Case A the steel stirrups yielded immediately after initial loading. Case B illustrates the opposite trend where a smaller load is carried by the straps. Case A and B show the same, expected trend with a steeper initial slope between 0 and 10 days and a shallower slope between 10 days and 20 years (i.e. creep at early loading stages has a larger impact) although the final strain for Case A is more than double that of Case B. However, the creep after 50 days has a greater impact in the Base Case. This reflects the fact that while in Case A the stirrups yield soon after creep begins and in Case B the stirrups never yield, in the Base Case the stirrups yield due to creep of the specimen. The level of strain in the steel transverse reinforcement is therefore an important consideration.

The experimental beams had the straps installed before they were loaded, which was a reasonable approach given the time available for testing. However, in a real retrofitting situation it is likely that the structure will have been under load for a considerable period of time before the retrofit is installed and the increased loading is applied. The resulting behaviour will depend on (i) the age of the structure when the retrofit is applied since this will determine the value of $\phi$ calculated using equation 6 and thus the change in transverse strain over time, (ii) the difference between the sustained load levels pre- and post-retrofit where if the structure is only being retrofitted to cope with higher peak transient loads or a very small increase in sustained load the long-term strain effects will be minimal and (iii) the strains in the steel transverse reinforcement (if any) prior to retrofitting. As indicated in the previous section, there are three possible outcomes for the transverse strains: (a) the strain always remains below the yield strain, (b) the strain starts out below the yield strain but then due to creep exceeds the yield strain or (c) the yield strain is exceeded immediately after the new load is applied. 
Modelling the sequential effects associated with the CFRP installation on an existing structure is complicated by the fact that the strain in the straps cannot be assumed to be the same as the strain in the existing transverse reinforcement plus a prestress term (as was the case for the experimental specimens) but is instead due only to the additional loading (which could be the

full load if the structure was entirely supported during the retrofit) plus a prestress term. As such the designer must perform the analysis in stages keeping careful track of the strains pre and post retrofit. The results of such an analysis (using a beam with the same properties as B8) are given in Fig. 9(b) for two potential retrofitting cases: (1) a structure that has carried 55kN of load for 20 years and then is retrofitted to carry an additional $35 \mathrm{kN}$ of load for 30 years and (2) a structure that has carried $55 \mathrm{kN}$ of load for a year before it is retrofitted to carry $35 \mathrm{kN}$ of additional load for 49 years. In each case the strap strain not including the strain due to prestress is plotted. Thus the plotted strain is zero at the time of retrofitting since at this time the strain in the strap is purely a function of the prestress until additional load is placed on the beam. Initially the angle of the compressive strut is steeper for Case 1 as a result of the extra 19 years of creep. The strain in the straps and the compressive strut angle then change by the same amount in both cases as the additional $35 \mathrm{kN}$ is placed on the beam, which is to be expected as creep will not affect 'instantaneous' changes in loading. The subsequent strap strain increase for Case 2 is double that of Case 1 due to both the duration of additional loading (30 years for Case 1 versus 49 years for Case 2) and the time at which the retrofit is applied. The increases in strain will be most significant for structures where the retrofit occurs at the same time as initial loading.

\section{Recommendations for further work}

The procedures detailed here are promising as the basis for predictions of the long-term deflections and strains in external CFRP reinforcement. However, further refinements and calibration against a range of experimental results are required to ensure a wider applicability. For example, an experimental program that investigated the effect of $a / d$ ratio on the short and long-term shear force carrying capacity enhancement provided by the straps would provide valuable insights into the role played by this important parameter. 
The modelling of flexure/shear interactions presents a further challenge. The assumed decoupling of these two effects worked well but creates inconsistencies in the approach. For example, since the ACI factor was derived based on the curve fitting of numerous experimental results, it is likely that shear deflections have been built into the method, albeit for cases where the shear deformations were likely to be smaller. Also, since the longitudinal strains influence the transverse strains any creep in flexure may cause a change in the force carried by the transverse reinforcement.

The transverse reinforcement was 'smeared' in the cracked element but there will be cases, for example if the transverse reinforcement spacing is large, where this assumption will not be appropriate. Furthermore, as presented, the model assumes that any section within a constant shear span will behave in the same way and does not consider disturbed regions.

\section{Conclusions}

In FRP shear-strengthened reinforced concrete structures, shear deflections can represent a significant component of the total deflection. Furthermore, over the longer term, time-dependent changes in the concrete material properties can lead to increased strains in FRP reinforcement. It is important to understand these time-dependent effects as this will influence the initial choice of the FRP design strains.

It was found that, with modifications to include prestressed CFRP straps and long-term concrete material properties, the modified compression field theory was able to predict the general trends observed in a series of experiments on T-beams strengthened with prestressed CFRP straps. However, a number of assumptions were incorporated in the predictions such as the decoupling of the flexural and shear strains and further validation and calibration is required before the applicability can be generalised. A preliminary parameter study suggests that the effect of loading and load history on the CFRP strap strains will require designers to consider carefully variables such as age at loading, the difference in pre- and post-retrofitted sustained loads, and the strains in the existing transverse reinforcement prior to the retrofit. 


\section{Acknowledgements}

The authors would like to thank EMPA for their support of this project. The first author is also indebted to the Cambridge Commonwealth Trust as well as Universities UK for providing financial assistance during the course of his studies.

\section{References}

American Concrete Institute (ACI) Committee 318. (2008). Building code requirements for structural concrete (ACI 318-08) and commentary (ACI318R-08), Farmington Hills, Mich.

Bentz, E. C. (2000). “Sectional analysis of reinforced concrete members.” Ph.D. thesis, Department of Civil Engineering, University of Toronto, Toronto, Canada.

Collins and Mitchell (1987). Prestressed Concrete Basics. Canadian Prestressed Concrete Institute, Canada.

Czaderski, C. and Motavalli, M. (2004). "Fatigue behaviour of CFRP L-shaped plates for shear strengthening of RC T-beams,” Composites Part B: Engineering, 35(4), 279-290.

De Lorenzis, L. and Nanni, A. (2001). "Shear Strengthening of Reinforced Concrete Beams with Near-Surface Mounted Fiber-Reinforced Polymer Rods,” ACI Structural Journal, 98(1), 60-68.

Dilger, W. (1967). “Anfangliche und nachtragliche Durchbiegung infolge Querkraft bei Stahlbetonbalken im Zustand II,” Beton- und Stahlbetonbau, 62(43), 212-217.

Hoult, N. (2005), Retrofitting of Reinforced Concrete Beams with CFRP Straps to Enhance Shear Capacity, PhD Thesis, University of Cambridge.

Hoult, N. and Lees, J. (2005). "Long-term Performance of a CFRP Strap Shear Retrofitting System," Seventh International Symposium on Fiber Reinforced Polymer for Reinforced Concrete Structures (FRPRCS-7). SP-230, American Concrete Institute International SP-230-40, 685-704.

Hoult, N.A. and Lees, J.M. (2007) “Approaches to modelling an unbonded CFRP strap shear strengthening system for RC beams”. In: 8th International Symposium on Fiber Reinforced Polymer Reinforcement for Concrete Structures, FRPRCS' 07, 16-18 July 2007, Patras, Greece.

Hoult, N.A. and Lees, J.M. (2009). "Efficient CFRP Strap Configurations for the Shear Strengthening of Reinforced Concrete T-Beams,” ASCE Journal of Composites for Construction, 13(1), 45-52.

Hoult, N.A. and Lees, J.M. (2009). "Modelling of an Unbonded CFRP Strap Shear Retrofitting System for RC Beams,” ASCE Journal of Composites for Construction. 13(4), 292-301. 
Kesse, G. and Lees, J.M. (2007). "Experimental behavior of reinforced concrete beams strengthened with prestressed CFRP shear straps,” ASCE Journal of Composites for Construction, 11(4), 375-383.

Kesse, G.K. and Lees, J.M. (2007). "Nonlinear FE Analysis of Cracks in Tension and Shear", Magazine of Concrete Research, 59(4), 233-244.

Khalifa, A., Gold, W.J., Nanni, A. and Abdel Aziz, M.I. (1998). “Contribution of Externally Bonded FRP to Shear Capacity of RC Flexural Members,” Journal of Composites for Construction, 2(4), 195-202.

Lees, J.M., Winistoerfer, A.U. and Meier, U. (2002) "External Prestressed CFRP Straps for the Shear Enhancement of Concrete", ASCE Journal of Composites for Construction, 6(4), 249-256.

Melo, G.S., Araujo, A.S. and Nagato, Y. (2003). "Strengthening of RC T Beams in Shear with Carbon Sheet Laminates (CFRP)," Proceedings of the Sixth International Symposium on FRP Reinforcement for Concrete Structures (FRPRCS-6), Singapore, 1, 477-486.

Neville, A.M., Dilger, W.H., and Brooks, J.J. (1983). Creep of plain and structural concrete, Construction Press, London, 361pp.

Nie, J. and Cao, C. S. (2000), “Deflection of Cracked RC Beams Under Sustained Loading”, ASCE Journal of Structural Engineering, 126(6), 708-716.

Stenger, F. (2000). Tragverhalten von Stahlbetonscheiben mit vorgespannter externer Kohlenstofffaser-Schubbewehrung. Doctor of Technical Sciences Thesis, Swiss Federal Institute of Technology (ETH), Zurich, Switzerland.

Triantafillou, T. C. (1998). "Shear Strengthening of Reinforced Concrete Beams Using EpoxyBonded FRP Composites,” ACI Structural Journal, 95 (2), 107-115.

Ueda, T., Sato, Y., Ito, T. and Nishizon, K. (2002). “Shear Deformation of Reinforced Concrete Beam”, J. Materials, Conc. Struct. Pavements, JSCE, No 711/v-56, 205-215.

Vecchio, F. J., and Collins, M. P. (1986). "The modified compression-field theory for reinforced concrete elements subjected to shear.” ACI J., 83(2), 219-231.

Winistoerfer, A.U. (1999). Development of non-laminated advanced composite straps for civil engineering applications. PhD Thesis, University of Warwick, Coventry, UK.

Yu, W.-W. and Winter, G. (1960). "Instantaneous and Long-Time Deflections of Reinforced Concrete Beams Under Working Loads.” J. of the ACI, 57(7), 29-50.

Zoeheary, A.A., Farahat, A.M. and El. Degwy, W.M. (1998), "Behaviour of Reinforced Concrete T-Beams.” Journal of Engineering and Applied Science, 45 (4), 513-531. 
Table 1 - Specimen properties

\begin{tabular}{|c|c|c|c|c|c|}
\hline Specimen & $f_{c u}(\mathrm{MPa})$ & $f^{\prime}{ }_{c}(\mathrm{MPa})$ & $f_{r}(\mathrm{MPa})$ & $\begin{array}{c}\text { Shear Force at } \\
\text { Failure }(\mathrm{kN})\end{array}$ & Failure Mode \\
\hline B1 & 24.8 & 19.8 & 3.36 & 88.2 & Shear \\
\hline B6 & 44.0 & 35.2 & 5.07 & 140.9 & Shear \\
\hline B7 & 36.1 & 28.4 & 2.85 & 134.7 & Flexure \\
\hline B8 & $42.9^{1} / 45.7^{2}$ & $34.3^{1} / 36.6^{2}$ & $4.59^{1} / 5.09^{2}$ & 131.2 & Flexure \\
\hline B9 & 41.7 & 33.4 & 5.70 & 139.2 & Flexure \\
\hline
\end{tabular}

${ }^{1}$ At start of sustained load test

${ }^{2}$ On day of failure load test

Table 2 - Long-term deflection predictions for the sustained (B8) and cyclic load specimen (B9)

\begin{tabular}{|c|c|c|c|c|c|c|c|}
\hline Specimen & $\begin{array}{c}\text { Time } \\
\text { (days) }\end{array}$ & $\begin{array}{c}\text { Exp } \\
\text { Defl } \\
(\mathrm{mm})\end{array}$ & $\begin{array}{c}\text { Pred Flex } \\
\text { Defl } \\
(\mathrm{mm})\end{array}$ & $\begin{array}{c}\text { Pred Flex } \\
\text { Defl / Exp } \\
\text { Defl }\end{array}$ & $\begin{array}{c}\text { Pred Shear } \\
\text { Defl } \\
(\mathrm{mm})\end{array}$ & $\begin{array}{c}\text { Pred Tot } \\
\text { Defl } \\
(\mathrm{mm})\end{array}$ & $\begin{array}{c}\text { Pred Tot } \\
\text { Defl / Exp } \\
\text { Defl }\end{array}$ \\
\hline \multirow{3}{*}{ B8 } & 0 & 15.4 & 10.1 & 0.66 & 1.5 & 11.6 & 0.75 \\
\cline { 2 - 8 } & 90 & 23.0 & 17.2 & 0.75 & 3.0 & 20.2 & 0.88 \\
\cline { 2 - 8 } & 180 & 23.9 & 18.7 & 0.78 & 3.3 & 22.0 & 0.92 \\
\cline { 2 - 8 } & 260 & 24.3 & 19.6 & 0.81 & 3.4 & 23.0 & 0.95 \\
\hline \multirow{2}{*}{ B9 } & 0 & 12.3 & 10.2 & 0.83 & 1.5 & 11.7 & 0.95 \\
\cline { 2 - 8 } & 12 & 14.9 & 11.5 & 0.77 & 2.3 & 14.3 & 0.96 \\
\hline
\end{tabular}




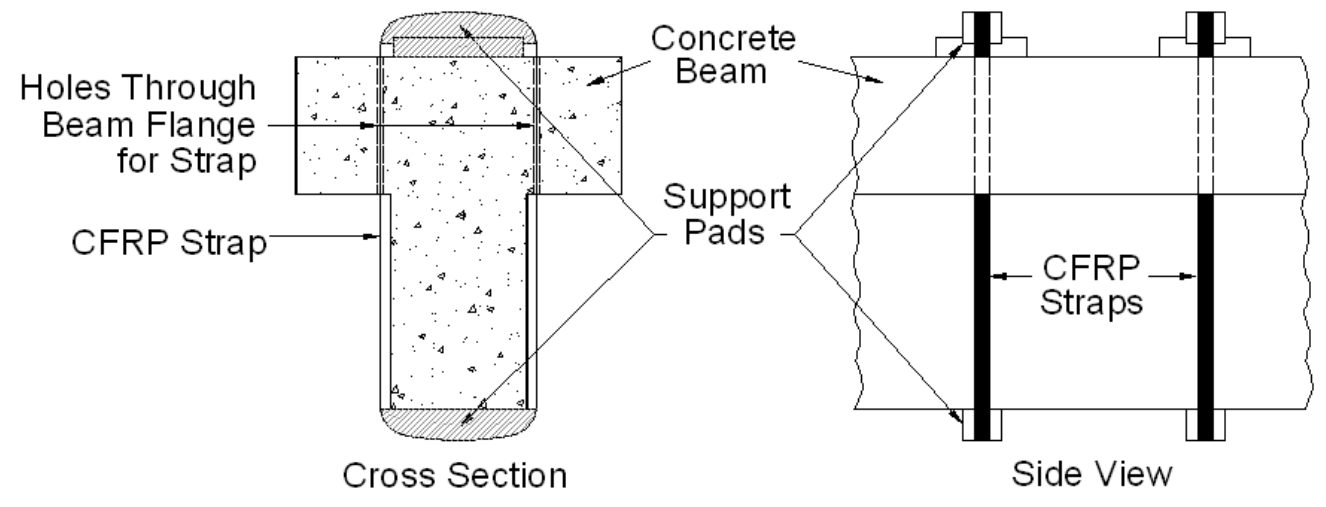

Fig. 1 - CFRP strap retrofitting technique

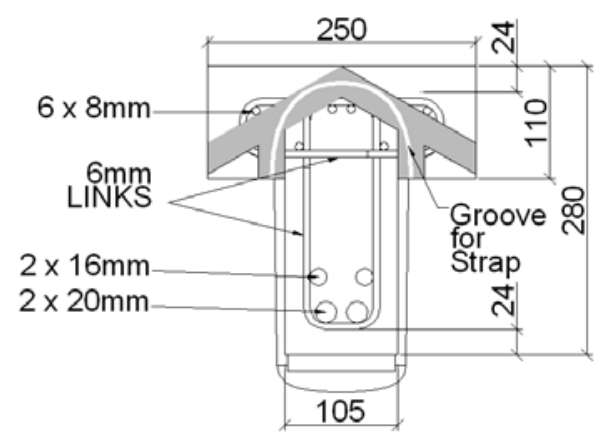

(a)

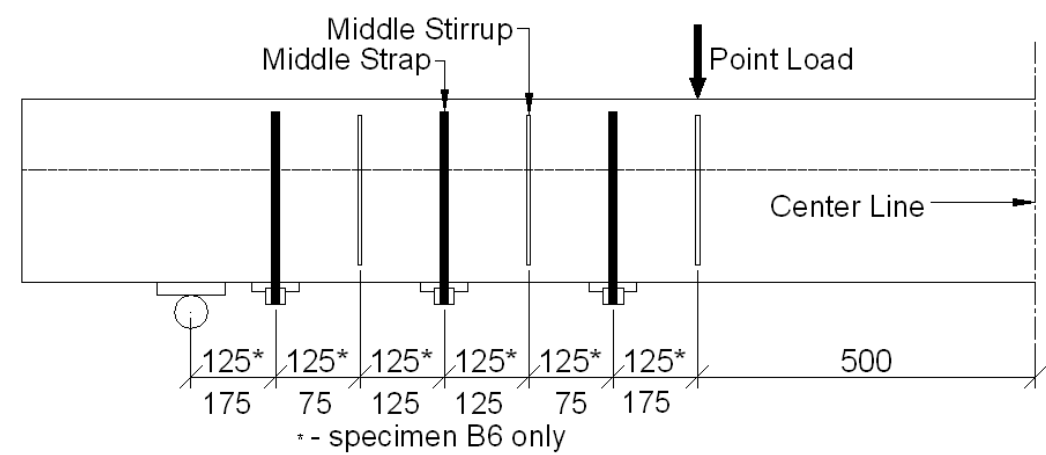

(b)

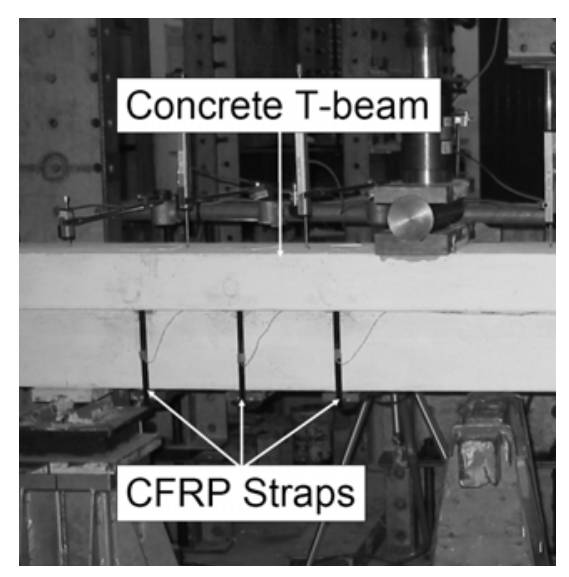

(c)

Fig. 2 - T-beam specimen (a) cross section and (b) transverse layout and (c) installed on beam 


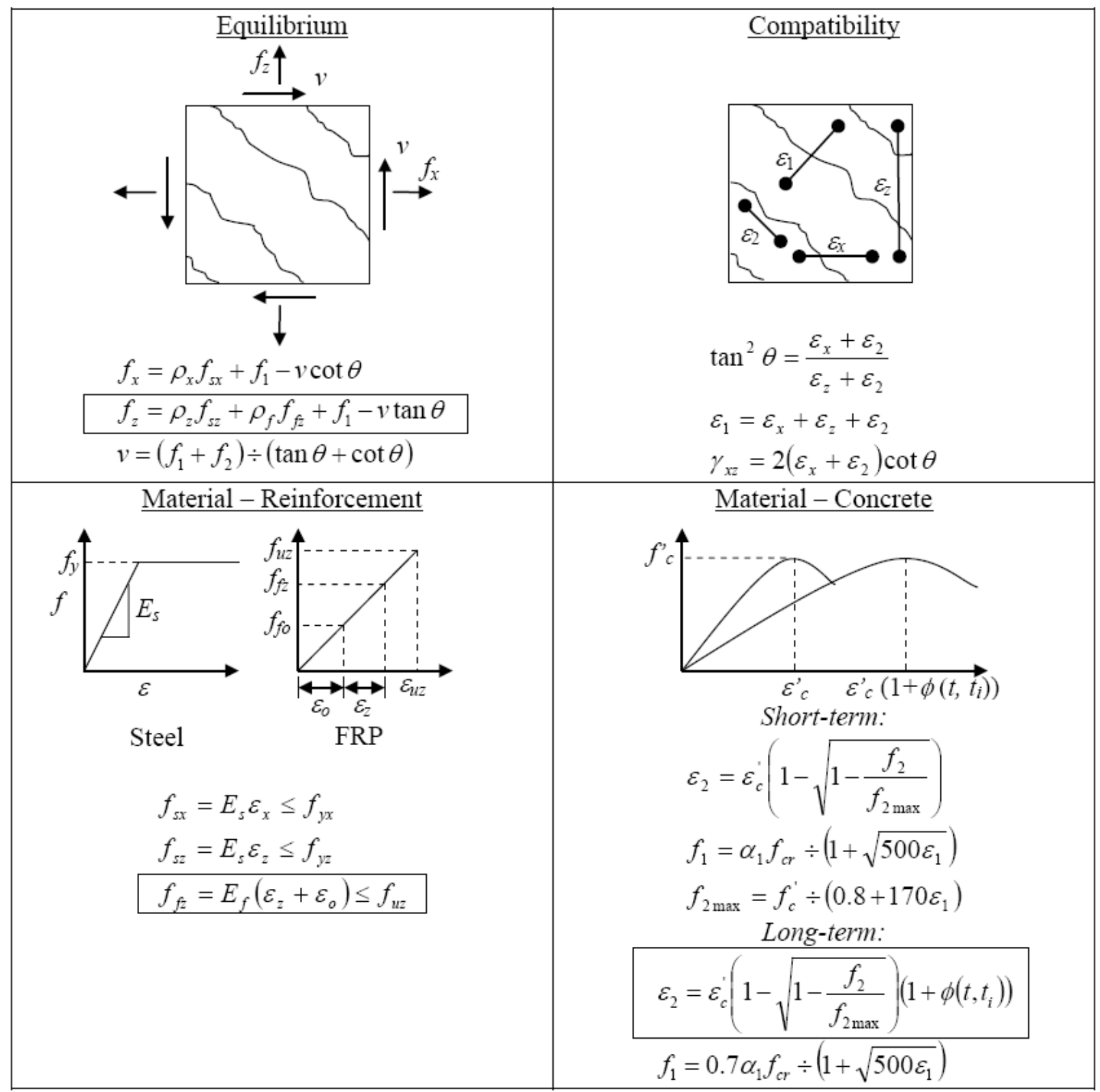

Fig. 3 - Modified Compression Field Theory after (Vecchio and Collins 1986; Collins and Mitchell 1987) and including revisions implemented in the current work (highlighted in boxes) 


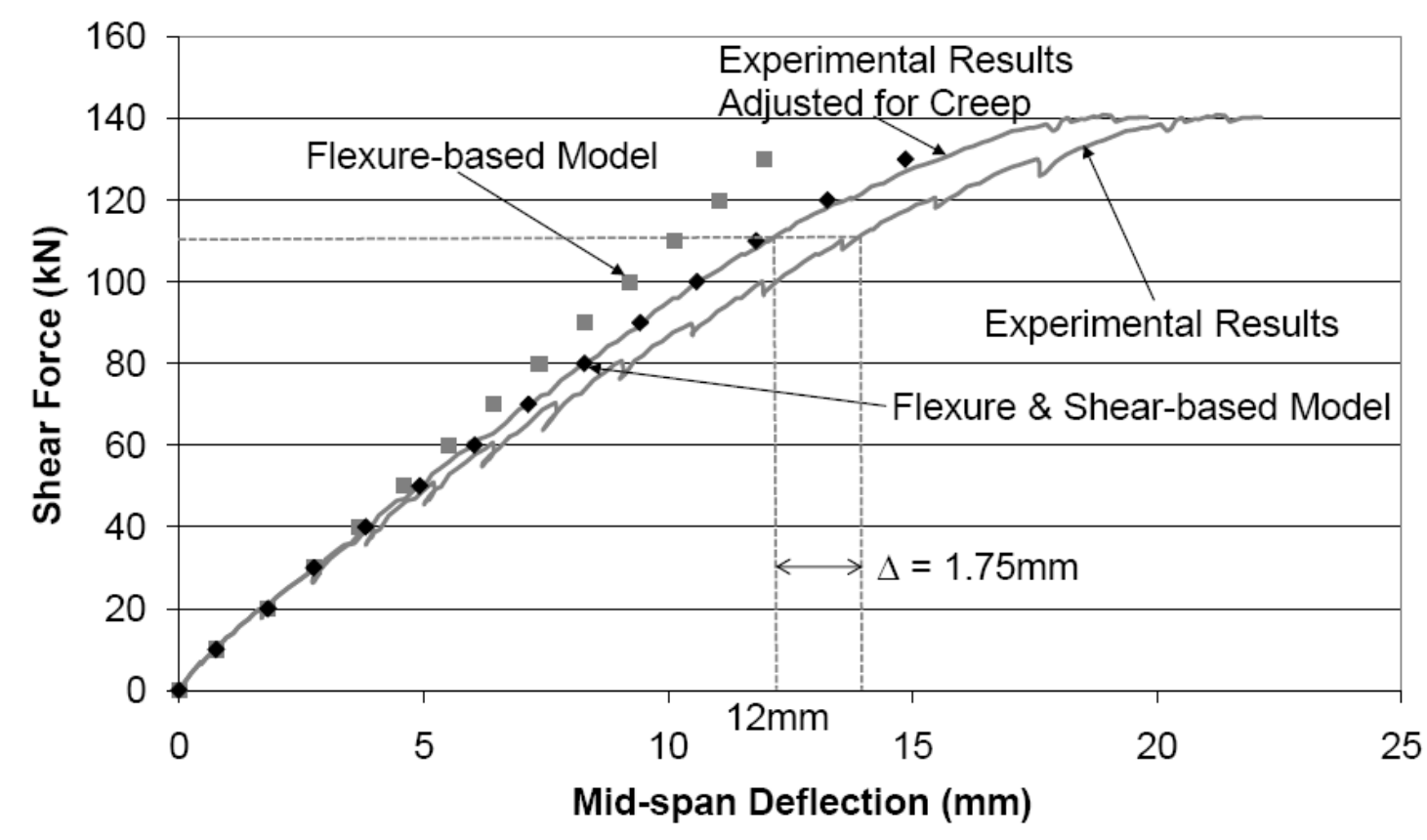

(a)

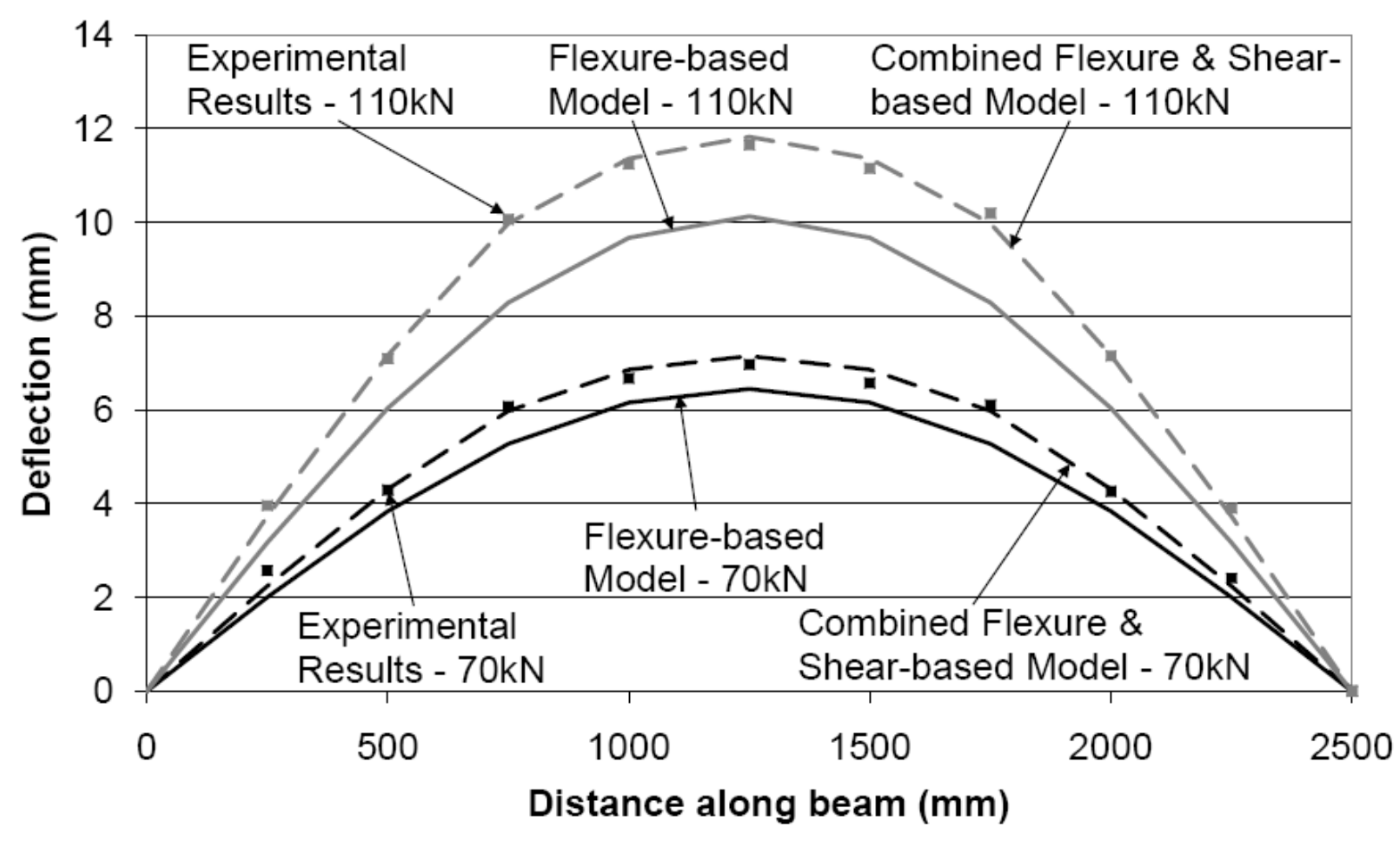

(b)

Fig. 4 - Experimental and predicted deflections for B6 (a) at mid-span and (b) along beam 


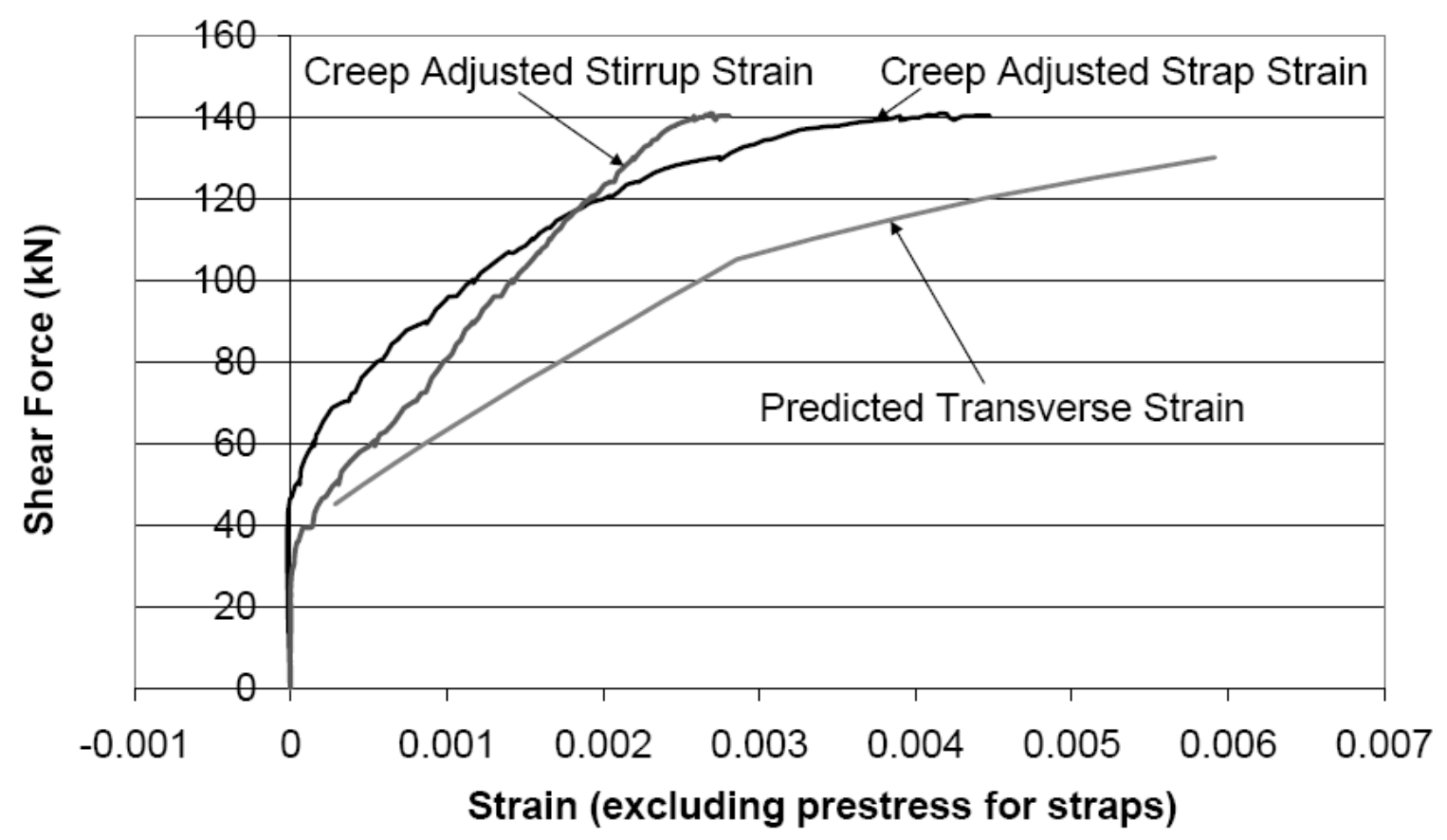

(a)

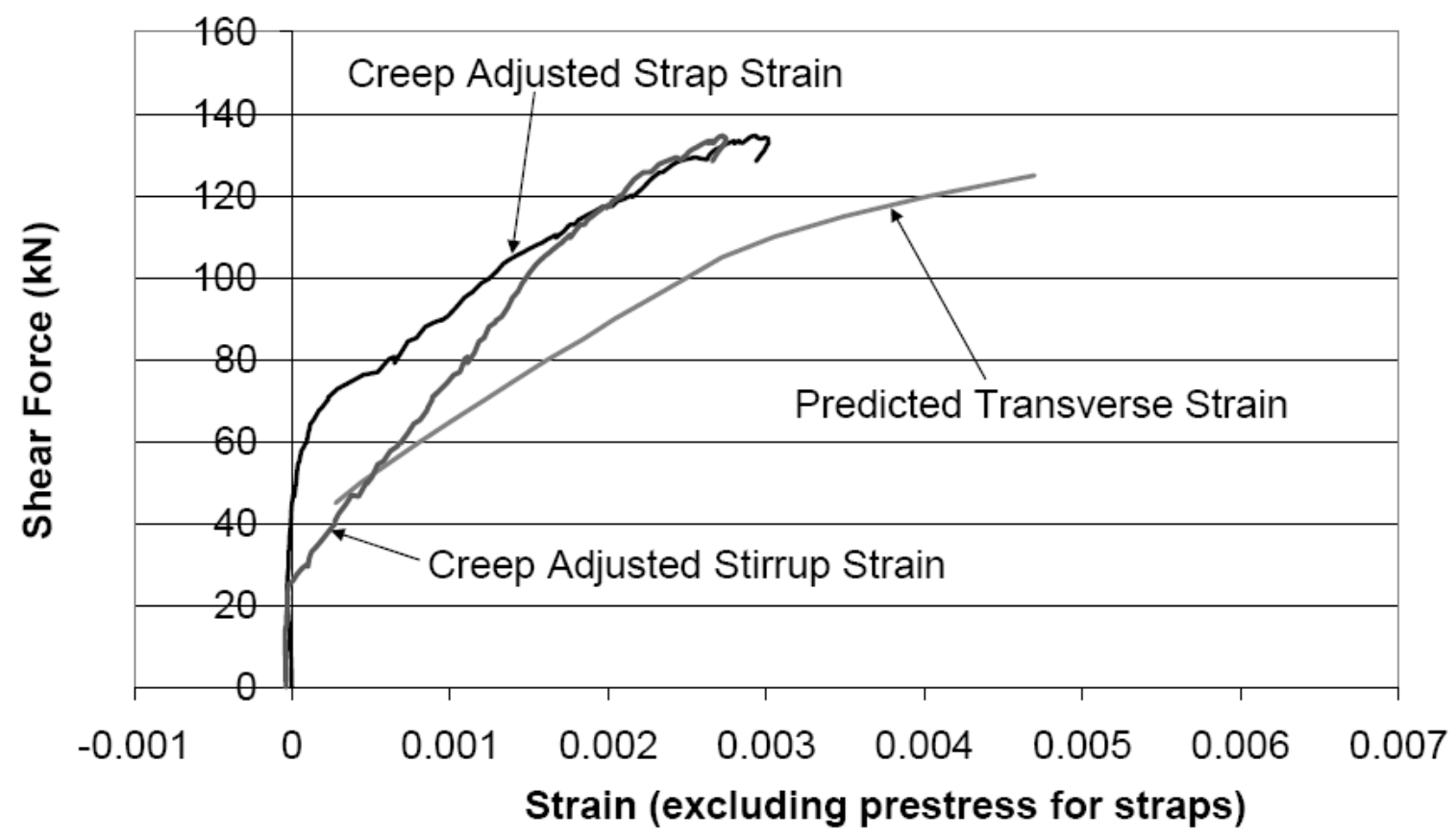

(b)

Fig. 5 - Experimental (adjusted for short-term creep) and predicted middle CFRP strap and transverse steel strains for (a) B6 and (b) B7 


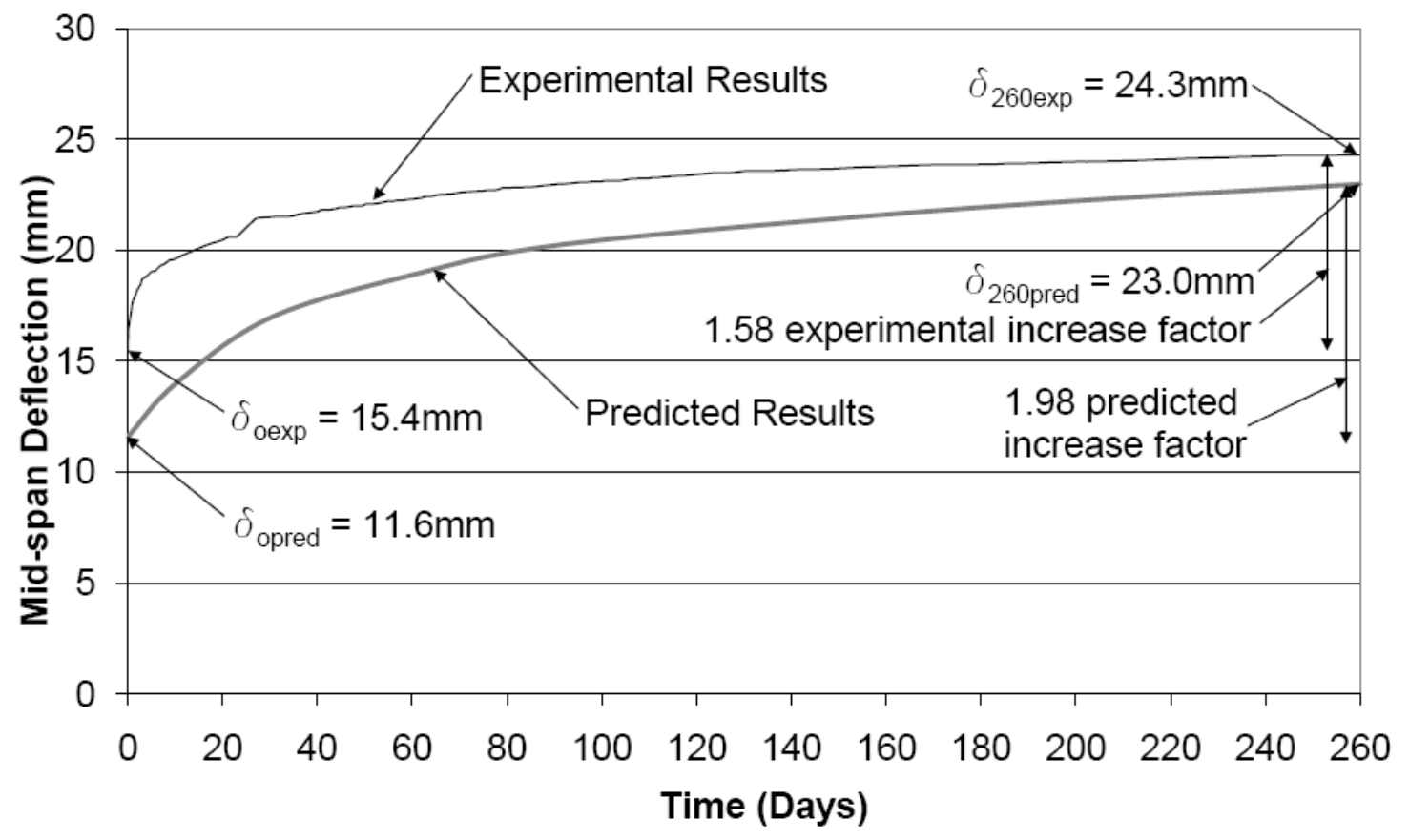

(a)

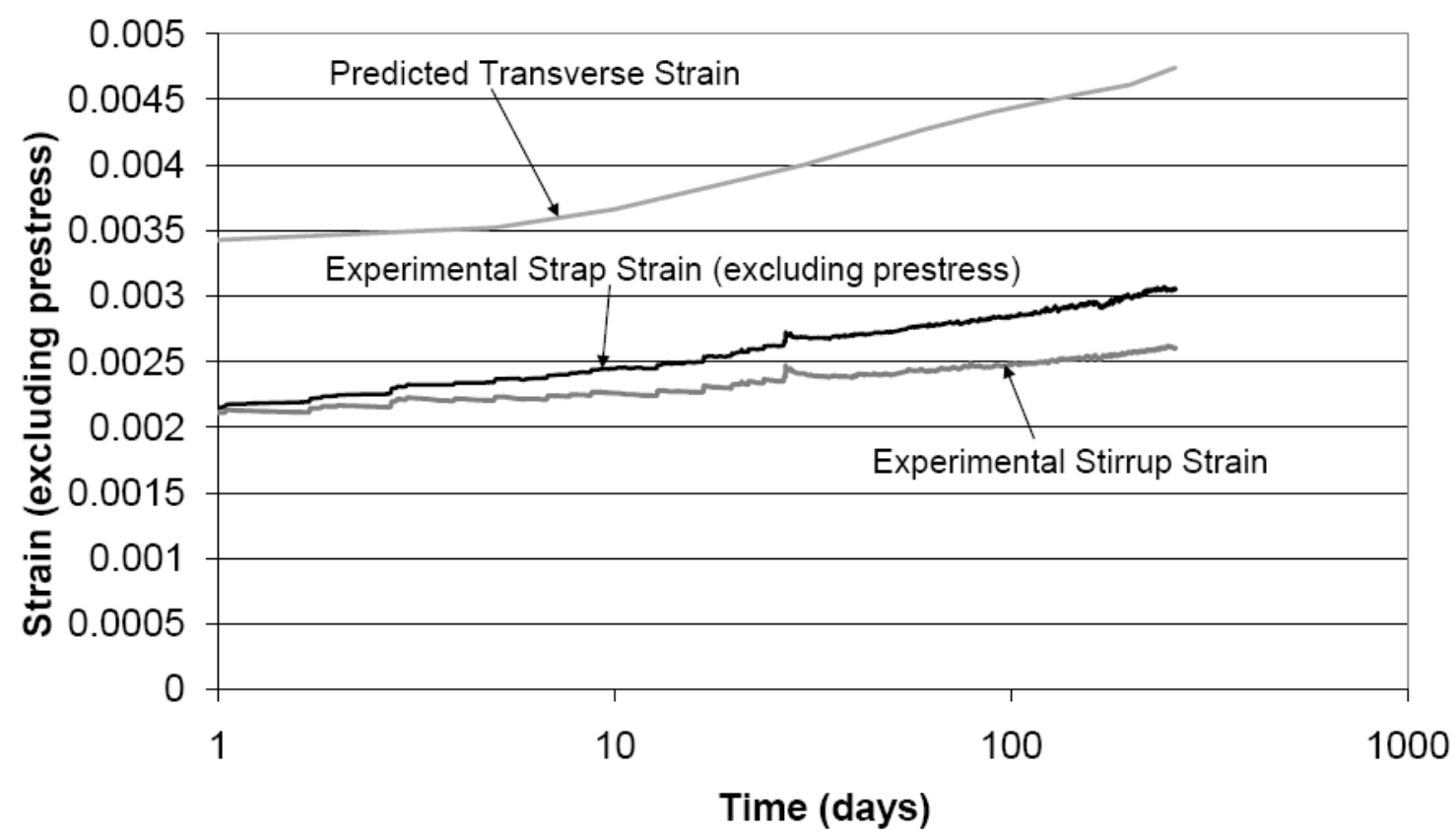

(b)

Fig. 6 -Sustained load beam B8, predicted versus experimental (a) deflection and (b) middle strap and stirrup strain 


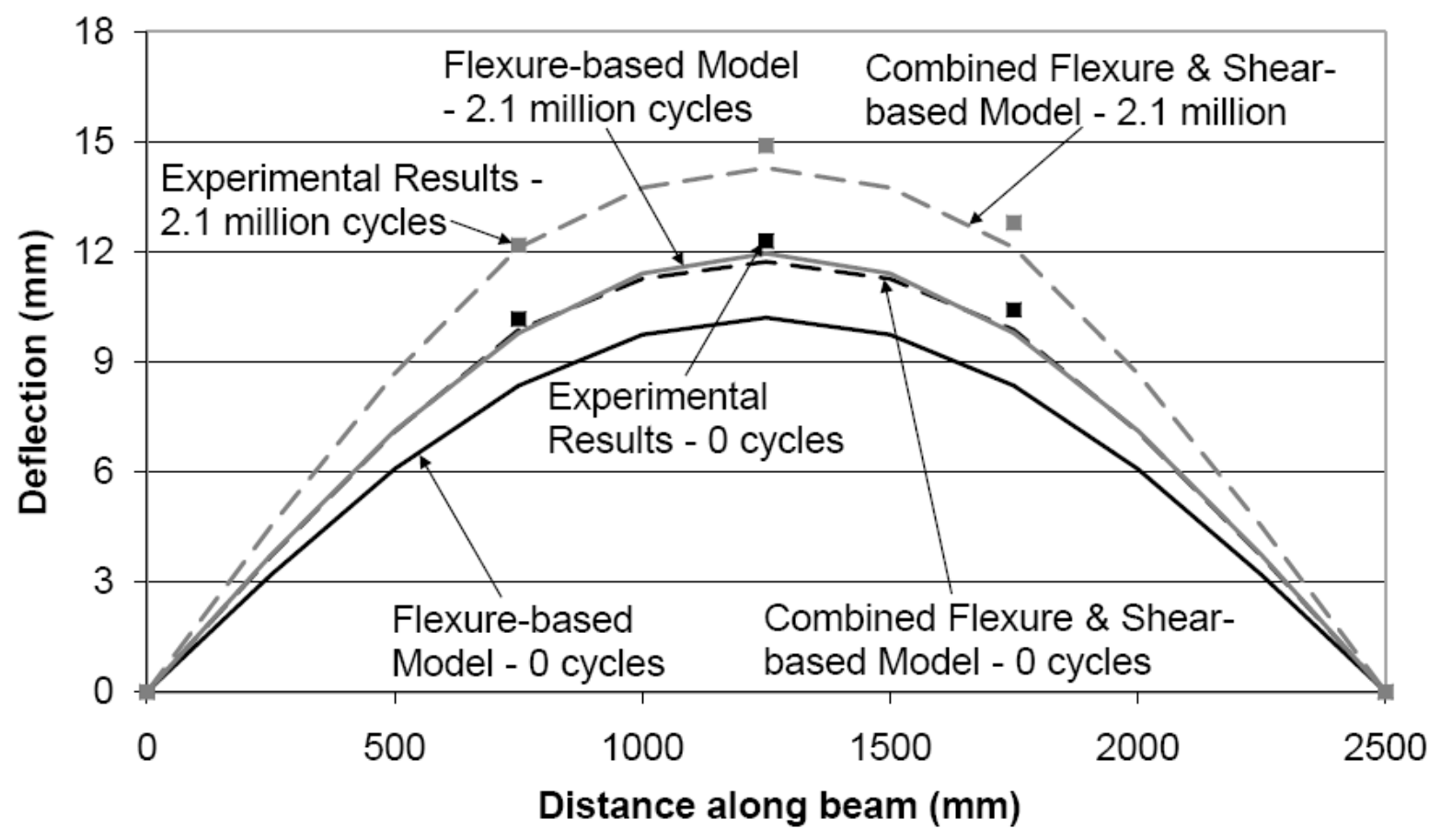

Fig. 7 - Experimental versus predicted deflections for B9 at 110kN

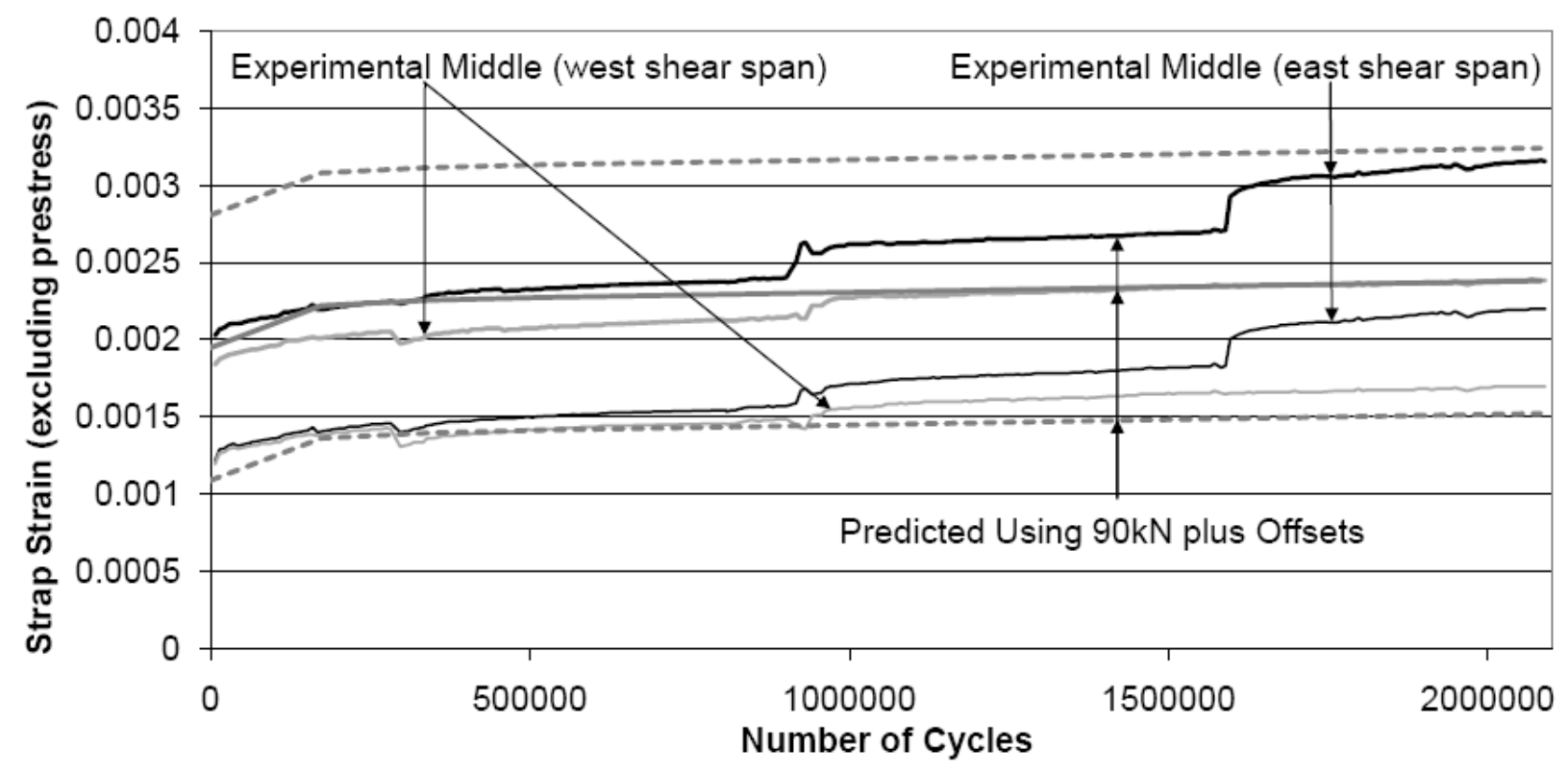

Fig. 8 - CFRP strap strain range versus number of cycles for B9 


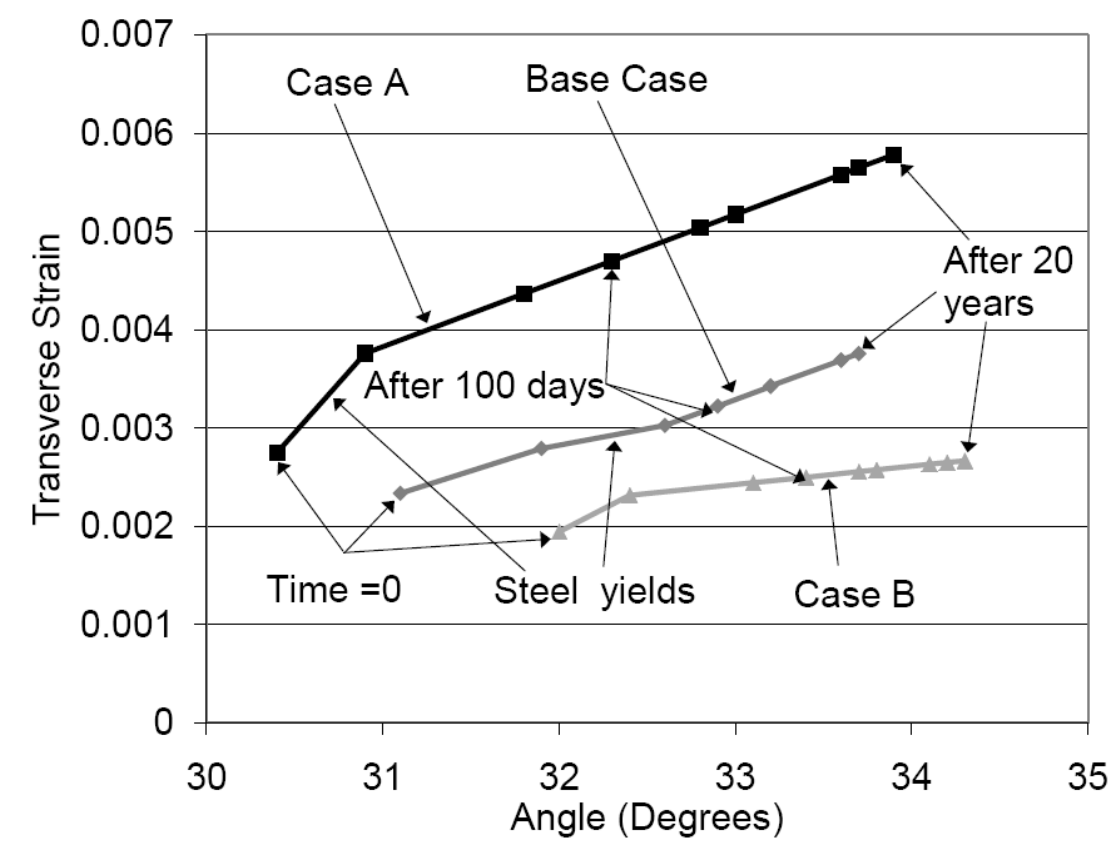

(a)

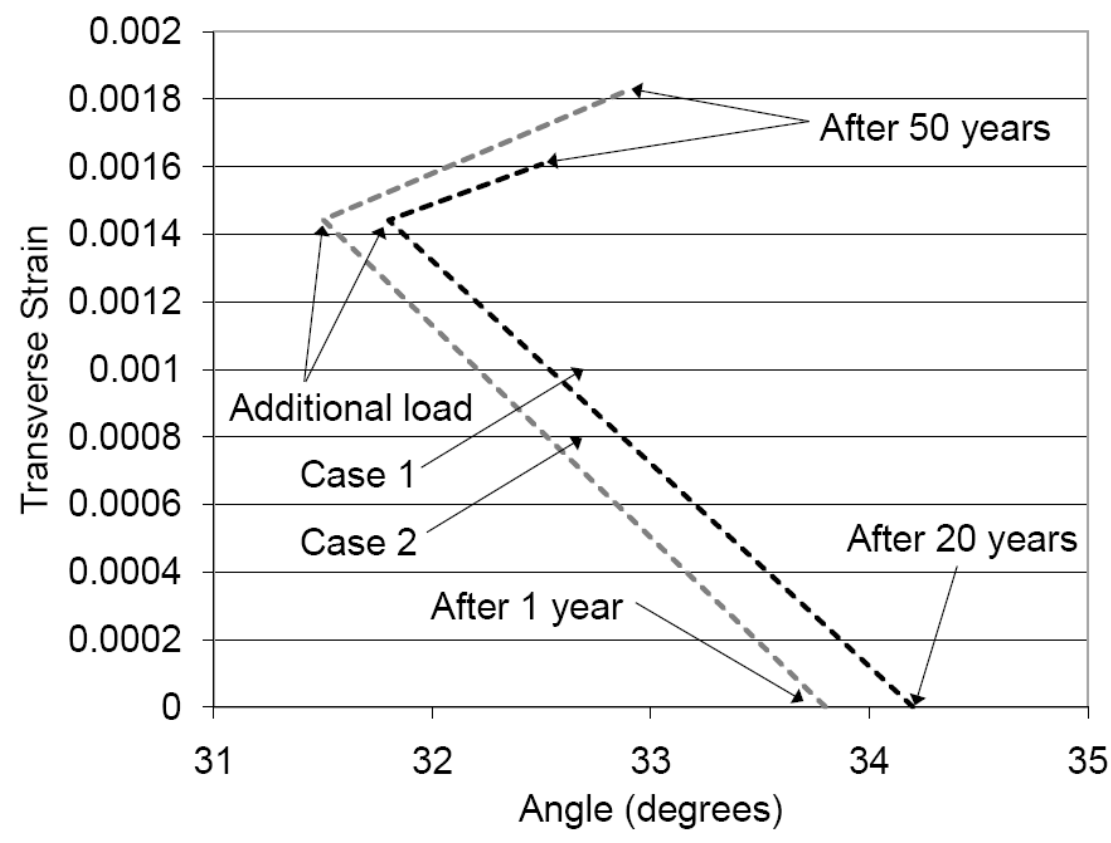

(b)

Fig. 9 - (a) Parametric and (b) long-term study 